\title{
Genética y genómica médica en el Perú
}

\section{Genetics and genomic medicine in Peru}

Correspondencia

Julio A. Poterico

Calle Jorge Buckley 185,

Miraflores, Lima, Perú

julio.poterico@upch.pe

Recibido: 01/05/2017

Aprobado: 07/06/2017

Citar como: Poterico JA, Purizaca-Rossillo N, TaypeRondan A. Genética y genómica médica en el Perú [carta]. Acta Med Peru. 2017;34(2):152-3

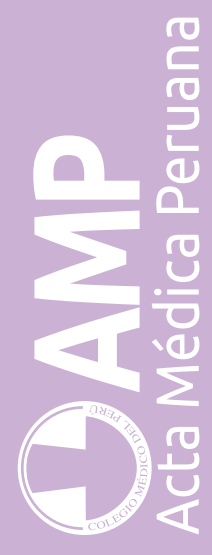

\author{
Julio A. Poterico ${ }^{1,2, a}$, Nelson Purizaca-Rossillo1,2,a, Alvaro Taype-Rondan³,b \\ 1 Universidad Peruana Cayetano Heredia. Lima, Perú. \\ 2 Instituto Nacional de Enfermedades Neoplásicas. Lima, Perú. \\ 3 CRONICAS Centro de Excelencia en Enfermedades Crónicas, Universidad Peruana Cayetano Heredia. Lima, Perú. \\ a Médico residente de Genética Médica, b Médico cirujano
}

\section{Sr. Editor:}

La genómica médica es una ciencia médica que aplica los conceptos de la genética y los conocimientos del genoma humano para la prevención, diagnóstico y tratamiento de muchas enfermedades del hombre; y no solo aquellas llamadas "raras" o "huérfanas".

El desarrollo de la genómica médica tiene el potencial de ser económicamente rentable, disminuyendo costos en el sistema de salud en algunas condiciones objetivo, y mejorando la calidad de vida del paciente; ya agrega el enfoque de bienestar familiar y social ${ }^{[1,2]}$. Por ello, la Iniciativa de Genómica Humana en la Salud Global de la Organización Mundial de la Salud (OMS) -disponible en: http://www. who.int/genomics/about/en/- resalta la importancia de la investigación y el uso de la genómica médica por parte de los sistemas de salud de cada país.

En el mundo, los estudios genómicos y el uso de las tecnologías relativas en el campo clínico se realizan con preponderancia en descendientes europeos. Esto limita el conocimiento, comparabilidad y el uso clínico de los hallazgos genómicos en otras poblacionales ${ }^{[3]}$. Sin embargo, en las últimas décadas algunos países de bajos y medianos ingresos han podido implementar exitosamente sistemas de salud con abordaje genómico y financiamiento estatal ${ }^{[4]}$. En Latinoamérica, Brasil representa un gran ejemplo de ello ${ }^{[5]}$. Asimismo, otros países latinoamericanos han creado programas nacionales de genómica médica para ciertas enfermedades, y en México se ha creado el Instituto Nacional de Medicina Genómica de México, pionero como tal en Latinoamérica ${ }^{[5]}$.

En el Perú, son pocas las entidades adecuadamente equipadas para realizar actividades de genética y genómica médica en la práctica clínica, y los esfuerzos al respecto se están desarrollando en tópicos puntuales y de una manera poco sostenible. Estos temas abarcan enfermedades neurológicas, cáncer hereditario y algunos temas pediátricos ${ }^{[5-8]}$. La Tabla 1 muestra la oferta de servicios que se brindan en la actualidad en los centros nacionales con actividades asistenciales de genética y genómica médica.

Asimismo, la investigación peruana en estas áreas emerge a paso lento, con instituciones representativas que se perfilan en dicho tema, como el Centro de Investigación de Genética y Biología Molecular de la Universidad San Martín de Porres, los Laboratorios de Investigación y Desarrollo de Ciencia y Tecnología de la Universidad Peruana Cayetano Heredia, el Instituto Nacional de Enfermedades Neoplásicas, el Instituto Nacional de Salud del Niño y el Instituto Nacional de Salud. Empero, estas entidades pocas veces han realizado investigaciones en conjunto.

La práctica clínica e investigación de la genómica médica en Perú continúan como desentendidas, y los esfuerzos por impulsarlas están fraccionados, débiles; y con una planificación poco perceptible en 
Tabla 1. Oferta de Servicios de Genética y Genómica Médica según establecimiento nacional en el Perú, con ejecución circunscrita al territorio nacional.

\begin{tabular}{|c|c|c|c|c|c|c|}
\hline Institución & $\begin{array}{l}\text { Consulta/ } \\
\text { Asesoría } \\
\text { genética }\end{array}$ & $\begin{array}{l}\text { Citogenética } \\
\text { convencional* }\end{array}$ & $\begin{array}{l}\text { Citogenética } \\
\text { molecular }\end{array}$ & $\begin{array}{c}\text { Biología } \\
\text { molecular-PCR* }\end{array}$ & $\begin{array}{l}\text { Secuenciamiento } \\
\text { Sanger** }\end{array}$ & $\begin{array}{l}\text { Secuenciamiento } \\
\text { masivo paralelo } \\
\text { (NGS)*** }\end{array}$ \\
\hline $\begin{array}{l}\text { Insituto Nacional de } \\
\text { Enfermedades Neoplásicas }\end{array}$ & Sí & Sí & Sí & Sí & Sí & No \\
\hline $\begin{array}{l}\text { Insituto Nacional del Niño - } \\
\text { Breña }\end{array}$ & Sí & Sí & $\mathrm{Si} \mathbf{i}^{\S}$ & Sí & No & No \\
\hline $\begin{array}{l}\text { Insituto Nacional del Niño - San } \\
\text { Borja }\end{array}$ & Sí & Sí & No & Sí & No & No \\
\hline $\begin{array}{l}\text { Instituto Nacional Materno } \\
\text { Perinatal }\end{array}$ & Sí & Sí & No & No & No & No \\
\hline $\begin{array}{l}\text { Instituto Materno Infantil San } \\
\text { Bartolomé }\end{array}$ & No & Sí & No & No & No & No \\
\hline $\begin{array}{l}\text { Instituto Nacional de Ciencias } \\
\text { Neurológicas }\end{array}$ & Sí & No & No & Sí & No & No \\
\hline $\begin{array}{l}\text { Hospital Nacional Guillermo } \\
\text { Almenara Yrigoyen }\end{array}$ & Sí & Sí & Sí & Sí & No & No \\
\hline $\begin{array}{l}\text { Hospital Nacional Edgardo } \\
\text { Rebagliati Martins }\end{array}$ & Sí & Sí & No & No & No & No \\
\hline
\end{tabular}

PCR: reacción en cadena de polimerasa

Se realizan pruebas de FISH (hibridazación in situ con fluorescencia)

$\S$ De enero a septiembre 2016 se realizaron pruebas de análisis por micromatrices cromosómicas (del inglés, "Chromosomal Microarray Analysis")

* Citogenética convencional (cariotipo): procedimiento con el cual se pueden visualizar los cromosomas en el microscopio y catalogar la alteración

** Secuenciamiento Sanger: procedimiento que permite analizar individualmente un gen, o grupos de genes. Laborioso y costoso.

***Secuenciamiento Masivo Paralelo (NGS): tecnología capaz de analizar paneles de genes, exomas clínicos, exomas completos y genomas completos, entre otros. Actualmente se utiliza mucho como primera línea de diagnóstico debido a las capacidades de detección y especificidad alcanzada.

las políticas sanitarias peruanas. Además, la genética y genómica médica exigen la interacción sincrónica y simbiótica de las actividades científicas y asistenciales.

Parece que la experiencia de otros países en estos temas nos enseñaría a generar medidas costo-efectivas, unificando estos esfuerzos dentro de un marco organizado, sostenible y coherente con las necesidades regionales-y por qué no hasta globales. ¿Podríamos pensar en el desarrollo de una institución peruana parecida al Instituto Nacional de Genómica Médica de México? Con esta carta al editor, abrimos el debate.

\section{Agradecimientos}

Manifestamos nuestra gratitud a nuestros colegas que permitieron mejorar el mensaje de este documento.

\section{REFERENCIAS BIBLIOGRÁFICAS}

1. Lu CY, Cohen JP. Can genomic medicine improve financial sustainability of health systems? Mol Diagn Ther. 2015;19(2):71-7.

2. Brand A, Evangelatos N, Satyamoorthy K. Public Health Genomics: the essential part for good governance in public health. Int J Public Health. 2016;61(4):401-3.

3. Bustamante CD, De La Vega FM, Burchard EG. Genomics for the world. Nature. 2011;475(7355):163-5.

4. Mitropoulos K, Al Jaibeji H, Forero DA, Laissue P, Wonkam A, Lopez-Correa $C$, et al. Success stories in genomic medicine from resource-limited countries. Hum Genomics. 2015;9:11.

5. Sequeiros J, Gibbon S, Clarke A. Genetics and ethics in Latin America. J Community Genet. 2015;6(3):185-7.

6. Gutiérrez M. Atlas de Dismorfología Pediátrica. Arch Argent Pediatr. 2013;111(5):461-2.

7. Manrique JE, Sullcahuamán-Allende Y, Limache-García A. Genetic counseling about cancer in Peru. Rev Peru Med Exp Salud Publica. 2013;30(1):118-23.

8. Galán-Rodas E, Dueñas M, Obando S, Saborio M. Tamizaje neonatal en el Perú: ¿hacia dónde vamos? Rev Peru Med Exp Salud Pública. 2014;30(4):724-5. 